\title{
Basic Fibroblast Growth Factor Ameliorates Learning Deficits in Basal Forebrain-Lesioned Mice
}

\author{
Akane Ishihara, Hiroshi Saito* and Nobuyoshi Nishiyama \\ Department of Chemical Pharmacology, Faculty of Pharmaceutical Sciences, University of Tokyo, \\ Bunkyo-ku, Tokyo 113, Japan \\ Received September 17, 1991 Accepted January 16, 1992
}

\begin{abstract}
The effect of basic fibroblast growth factor (bFGF) treatment on memory and learning performance ability was investigated in basal forebrain (BF)-lesioned mice. Eight-week-old male ddY mice underwent bilateral BF lesions by delivery of radiofrequency current. Basic FGF ( 5 or $50 \mathrm{ng} / \mathrm{side}$ ) was microinjected into the same location immediately after lesioning. From fifteen days after the treatment, a step-through type passive avoidance test was performed daily for 10 days. Lesioned animals showed severe impairment in the acquisition process in this task, but not in the retention process. Basic FGF improved the step-through performances; step-through latency was elongated in a dose-dependent manner on the first test trial day and the mean time required to reach the acquisition criterion was shorter than in the vehicle-treated control group. However, bFGF did not alter the cortical choline acetyltransferase (ChAT) activity decrement induced by BF lesion. These results suggest that bFGF ameliorates the memory deficit without affecting the cortical ChAT activity.
\end{abstract}

Keywords: Basal forebrain lesion, Basic fibroblast growth factor, Step-through test, Choline acetyltransferase activity, Memory deficit

Alzheimer's disease has a characteristic pattern of brain degeneration associated with progressive impairment of cognitive functions. The loss of cholinergic cells in the basal forebrain (BF) and a reduction of presynaptic cholinergic markers in the neocortex have been found in patients with Alzheimer's, and these changes were found to be correlated with the degree of dementia in clinical studies $(1-3)$. The basal forebrain cholinergic system has been demonstrated to play an important role in memory function, and extensive investigations using rats and monkeys indicate that experimental lesioning of this region causes severe deficits in many kinds of learning tasks (4-8). Furthermore, we have recently succeeded in producing a murine model of these learning deficits (9).

Basic fibroblast growth factor (bFGF) is one of the mitogenic proteins found in adult rat brain tissue, and it can promote proliferation of various types of cells $(10$, 11). Immunoreactivity of this factor is localized in neurons $(12,13)$ and rises rapidly after brain injury (14). In addition, bFGF has been demonstrated to

\footnotetext{
${ }^{*}$ To whom correspondence should be addressed.
}

promote survival and neurite outgrowth of cultured CNS neurons from several regions $(15-17)$ and to rescue medial septal neurons after fimbria fornix transection $(18,19)$. Among the various neurotrophic factors, nerve growth factor (NGF) is the best-characterized substance and has been reported to ameliorate memory impairment of aged rats in Morris's water maze test and also to prevent the atrophy of BF cholinergic neurons (20). However, the influence of bFGF on memory function has not yet been demonstrated at the whole animal level.

In the present study, we investigated the effects of bFGF on $\mathrm{BF}$ lesion-induced learning impairment in mice.

\section{MATERIALS AND METHODS}

\section{Animals}

Male ddY mice weighing 35-39 g, 8 weeks old at the start of the experiments, were used (SLC, Hamamatsu, Japan). Animals were housed in groups of 5 in metal cages $(30 \times 20 \times 10 \mathrm{~cm})$ in a temperature- $\left(22 \pm 1^{\circ} \mathrm{C}\right)$ and humidity- $(55 \pm 5 \%)$ controlled room. Food (CE- 
2, Clea Japan, Inc., Tokyo, Japan) and water were available ad libitum.

\section{Drugs}

Basic FGF (recombinant human basic fibroblast growth factor, mutein $\operatorname{CS} 23$ (21)), was a gift from Takeda Chemical Industries, Ltd. (Osaka, Japan). Other chemicals used were obtained from commercial sources.

\section{BF lesion}

Under anesthesia with a mixture of ketamine and xylasine ( 80 and $7 \mathrm{mg} / \mathrm{kg}$, respectively, i.m.), mice underwent bilateral BF lesion by delivery of a radiofrequency current using a lesion generator (RADIONICS Inc., Burlington, USA). The coordinates of the electrode placements were: $0.8 \mathrm{~mm}$ posterior to the breg$\mathrm{ma}, \pm 2.8 \mathrm{~mm}$ lateral to the sagittal suture, and $4.3 \mathrm{~mm}$ below the dura, with the incisor bar placed at $2.2 \mathrm{~mm}$ ventral to the horizontal plane. The stainless steel electrode $(0.25 \mathrm{~mm}$ diameter) was inserted into the brain, and the tip of it was heated at $70^{\circ} \mathrm{C}$ for $60 \mathrm{sec}$. For the sham-operated mice (SHAM, $\mathrm{n}=15$ ), the inserted electrode was not heated. Basic FGF was injected bilaterally in the lesioned position immediately after lesion through a stainless steel cannula (O.D. $0.3 \mathrm{~mm}$ ) connected via polyethylene tubing to a $10-\mu 1$ Hamilton syringe. Basic FGF treated on each side with 5 or $50 \mathrm{ng}$ FGF per $\mu 1$ of PBS containing $0.01 \%$ BSA, $\mathrm{n}=15$, designated as FGF 5 and FGF 50, respectively) was applied at the speed of $0.5 \mu \mathrm{l} / \mathrm{min}$. The cannula was left in place for $5 \mathrm{~min}$ after injection. Vehicle was injected into the SHAM and lesioned control group (FGF 0, n $=15$ ). Control mice received anesthesia only (CONT, $\mathrm{n}=15$ ). Commercially available milk was given twice a day to the BF-lesioned mice for 12 days after surgery (total $2 \mathrm{ml} /$ day, p.o).

\section{Learning performance experiments}

After the body weights of the lesioned mice had recovered, 15 days after the operation, they were submitted to a step-through type passive avoidance learning task. The step through test was performed according to the method of Segawa et al. (22) following the measurement of motor activities with a tilting-type ambulometer (O'Hara \& Co., Ltd., Tokyo, Japan) for $30 \mathrm{~min}$.

A two-compartment step-through type avoidance apparatus (PA M1, O'Hara \& Co., Ltd., Tokyo, Japan) was used. In the acquisition trial, mice were placed in a front illuminated chamber, and when they entered the rear dark compartment, an $36 \mathrm{~V}$ footshock (max. $0.2 \mathrm{~mA}$ ) was delivered through the grid floor.
The time elapsed before they entered the dark compartment was recorded. From $24 \mathrm{hr}$ after this acquisition trial, the mice were submitted to a testing session consisting of a daily testing trial for ten days at the same time of day. During the testing session, the punishing footshock was always given to the mice which stepped through into the dark compartment. In the testing trial, each mouse was placed in the light compartment, and the latency to enter the dark compartment was measured with the ceiling score of $300 \mathrm{sec}$. This ceiling score of $300 \mathrm{sec}$ was regarded as a criterion of acquisition and a mouse that did not enter the dark compartment for $300 \mathrm{sec}$, that is, a mouse which did not receive the punishing electroshock for the first time, was regarded as having reached the criterion. The number of days taken to reach this criterion ("Acquisition") was measured as a parameter of the acquisition ability of this task. The mean number of days during which the mice made no error after they had once attained the above-mentioned criteria was measured as a parameter of retention ability ("Retention").

\section{ChAT activity and histological study}

After the behavioral tests, 31 days after lesioning, the mouse was decapitated after cervical dislocation and the brain was removed rapidly. The anterior and posterior cerebral cortices were dissected immediately, and their ChAT activities were measured by the method of Fonnum (23). Protein content was determined by using a dye method with BSA as the standard (24). The subcortical region was immersed in Bouin's fixative. Eightmicron paraffin sections were cut and stained with hematoxylin-eosin (H.E.) and anti-glial fibrillary acidic protein (GFAP) antibody (Sanbio bv, Uden, Netherlands). The location and histological alterations of the lesioned site were assessed by microscopic observation. The volume of the lesioned area was measured by using an image analyzer (MGA-1300, Mutoh Kohgyo, Japan).

\section{Statistics}

Mann-Whitney's $U$-test was used for statistical analysis of the step-through latency. Analysis of variance (ANOVA) followed by Duncan's test was used for motor activity and ChAT activity.

\section{RESULTS}

Body weight of the operated mice decreased soon after surgery for about one week. This reduction of body weight can often be seen in BF-lesioned animals. Most mice recovered their body weight within 15 days after operation. Basic FGF treatment did not affect this 
change of body weight (data not shown). However, 2, 2 and 5 animals died in FGF 0 , FGF 5 and FGF 50 , respectively.

The lesioned area was typically observed in the ventromedial region of the globus pallidus, which corresponds to the rodent's BF (Fig. 1).

Although animals were not evaluated quantitatively for the alteration of shock sensitivity in this study, no behavioral differences were observed in their responses among these five groups when the punishing electric shock was delivered from the grid floor of the passive avoidance apparatus.

In the step-through test, mean latency to enter the dark chamber in the acquisition trial did not differ in each group. However, in the first testing trial performed $24 \mathrm{hr}$ later, the latency in FGF 0 was shorter than that of SHAM and CONT. On the other hand, bFGF-treated groups exhibited longer latency in a dosedependent manner, and the higher dosage of bFGF significantly elongated the step-through latency (Fig. 2, P $<0.05$ ). Lesioned mice took more trials to reach the criterion than SHAM and CONT, while bFGF-treated

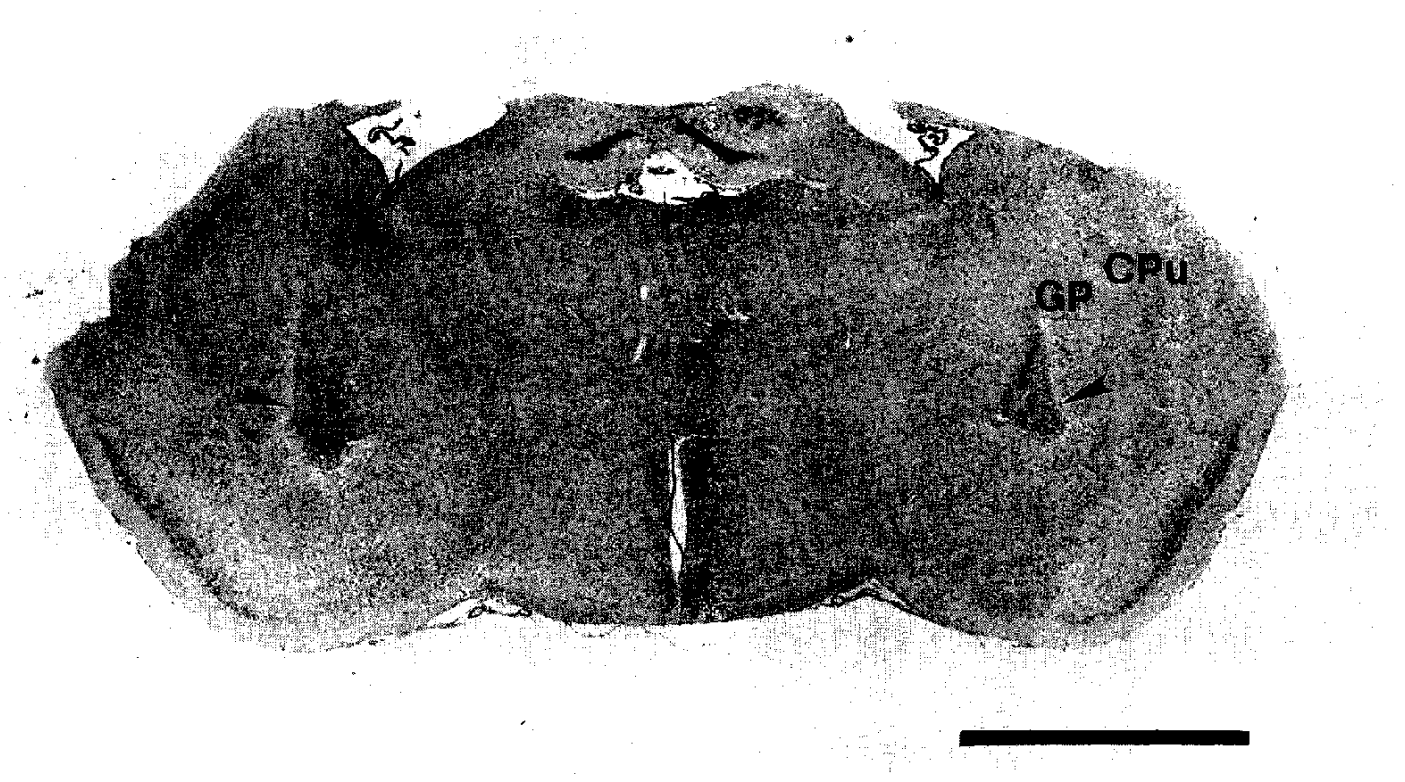

Fig. 1. Typical location of the lesioned area. Eight-micron paraffin sections of FGF 5 were stained with H.E. 31 days after the operation. The bar represents $2 \mathrm{~mm}$, and the arrowheads indicate the lesioned area. The cerebral cortex was removed to determine the ChAT activity. Abbreviations: GP, globus pallidus; CPu, caudate putamen.

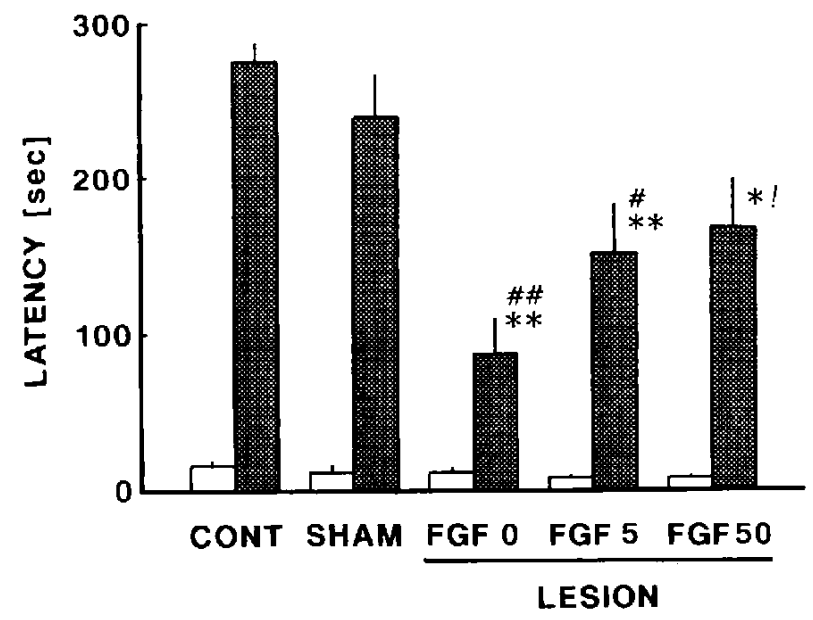

Fig. 2. Effect of bFGF on step-through test in BF-lesioned mice. Mice were placed in the illuminated chamber of a two-compartment step-through apparatus, and the mean latency to enter the dark chamber in the acquisition (open column) and the first retention trial (dot column, performed 24 hours later) were measured with the ceiling score of $300 \mathrm{sec}$. The bars indicates S.E. Abbreviations: CONT, anesthesia only; SHAM, sham-operated with vehicle injection; FGF 0, vehicle injection; FGF 5 and FGF 50, 5 and $50 \mathrm{ng} / \mu \mathrm{l}$, respectively, $1 \mu \mathrm{l} /$ side, of bFGF injection. $\#: \mathrm{P}<$ $0.05,{ }^{\# \#}: \mathbf{P}<0.01$ vs. SHAM, ${ }^{*}: \mathrm{P}<0.05,{ }^{* *}: \mathrm{P}<0.01$ vs. CONT, ': P<0.05 vs. FGF 0, (Mann-Whitney's $U$-test). 
mice acquired this task significantly faster than FGF 0 (Table 1, "Acquisition"). However, BF lesioning resulted in little or no deterioration in the retention process. Basic FGF had no effect on this parameter (Table $1)$.

The ChAT activities in anterior and posterior cerebral cortices are summarized in Table 2 . In the anterior cerebral cortex, ChAT activity was decreased in FGF 0 (ca. 20\%), while this decrement was less than $10 \%$ in the posterior cortex. Basic FGF treatment did not affect the cortical ChAT activity in either the anterior or posterior cortices except that the higher dose of bFGF deteriorated the ChAT activity decrease in the posterior cortex.

BF lesioning caused a decrease of motor activity during the period when the passive avoidance test was performed. However, bFGF did not affect this reduction (Fig. 3).

Extensive gliosis was observed in the injured area of the lesioned groups (Fig. 4). In H.E. staining, many cells with small nuclei were seen in and around the lesioned area and they formed a scar. In the inner part

Table 1. Acquisition and retention in step-through passive avoidance lest

\begin{tabular}{lll}
\hline & "Acquisition" & "Retention" \\
\hline CONT & $1.3 \pm 0.1$ & $3.8 \pm 0.8$ \\
SHAM & $1.4 \pm 0.2$ & $3.0 \pm 0.8$ \\
FGF 0 & $5.1 \pm 0.9^{\# * * *}$ & $2.2 \pm 0.6$ \\
FGF 5 & $2.3 \pm 0.3^{\# * *}$ & $2.8 \pm 0.8$ \\
FGF 50 & $3.9 \pm 1.0^{\# *}$ & $2.0 \pm 0.8$ \\
\hline
\end{tabular}

"Acquisition" and "Retention" indicate the mean number of days until the micc reached the criterion and the mean number of days until the mice made the first crror from the time when they had attained this criterion, respectively. Results are given as means \pm S.E. [days]. \#\# $: \mathrm{P}<0.01$ vs. SHAM, ${ }^{*}: \mathrm{P}<0.05,{ }^{* *}: \mathrm{P}<0.01$ vs. CONT, ' $: \mathrm{P}<0.05$ vs. FGF 0 , Mann-Whitney's $U$-test. For abbreviations, sce the legend to Fig. 2 .

Table 2. Changes in choline acetyltransferase activity in the cerebral cortex

\begin{tabular}{lll}
\hline & \multicolumn{1}{c}{ Anterior cortex } & \multicolumn{1}{c}{ Posterior cortex } \\
\hline CONT & $0.265 \pm 0.015$ & $0.286 \pm 0.008$ \\
SHAM & $0.268 \pm 0.011$ & $0.292 \pm 0.007$ \\
FGF 0 & $0.218 \pm 0.012^{\# \# *}$ & $0.263 \pm 0.009^{\#}$ \\
FGF 5 & $0.219 \pm 0.008^{\# * *}$ & $0.268 \pm 0.009$ \\
FGF 50 & $0.215 \pm 0.014^{\# *}$ & $0.246 \pm 0.009^{\# * *}$ \\
\hline
\end{tabular}

Results are given as means $\pm \mathrm{S}$.E. ( $\mathrm{pmol} / \mu \mathrm{g}$ protein $/ \mathrm{min}$ ). \#: $\mathrm{P}<0.05$, \#\#: $\mathrm{P}<0.01$ vs. SHAM, ${ }^{*}: \mathrm{P}<0.05,{ }^{* *}: \mathrm{P}<$ 0.01 vs. CONT, Duncan's multiple range test. See the legend to Fig. 2 for abbreviations.

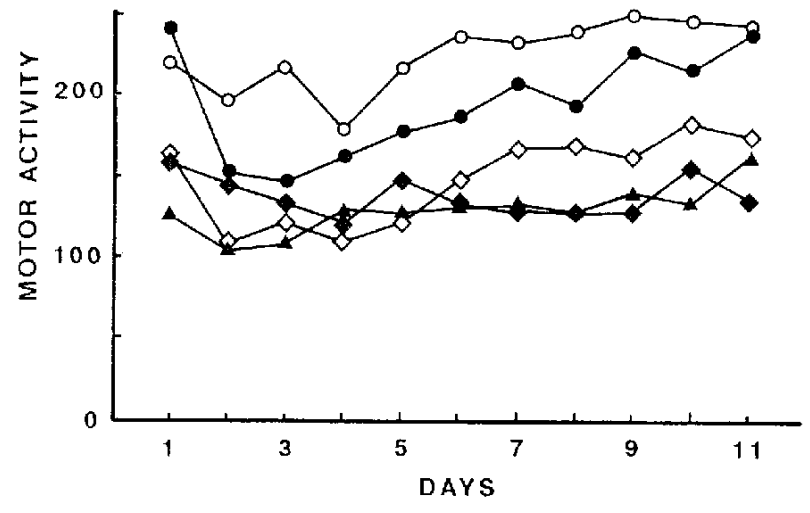

Fig. 3. Motor activity during behavioral test. $\bigcirc$, CONT; SHAM; $\Delta$, FGF 0; $\bigcirc$, FGF 5; $\diamond$ FGF 50. See the legend to Fig. 2 for explanations. Motor activity was measured with a tilting-type ambulometer for $30 \mathrm{~min}$ before the passive avoidance tests. FGF (), FGF 5 and FGF 50 exhibited significantly lower motor activity than CONT and SHAM on almost all days during the testing period (Duncan's multiple range test).

of the lesion, many processes of GFAP-positive astrocytes exhibited a net-like formation and scarcely any BF magnocellular neurons could be seen (Fig. 4). GFAP-positive processes also extended to the outside of the scar. Some blood vessels were seen in the lesioned area. However, there seemed to be no distinct pathological difference among FGF 0 , FGF 5 and FGF 50. The average lesioned volumes of the groups are given in Table 3 , and no significant differences were found among the groups.

\section{DISCUSSION}

Basic FGF ameliorated the learning performance impairment induced by BF-lesion in the step-through test. It elongated the step-through latency in the first testing trial and enhanced the attainment of the acquisition criterion. However, bFGF improved only the acquisition process, which was impaired by $\mathrm{BF}$ lesion, and it had no influence on the retention process, upon which the lesion was ineffective. Though the influence of this factor on memory performance in normal mice has not yet been investigated in the same paradigm, these data suggest that bFGF ameliorates the deterioration of learning performance but does not enhance the normal memory function.

In some BF lesion experiments, motor hyperactivity 2 or 3 weeks after operation has been reported $(25,26)$. However, in the current experiment, lesioned mice showed significantly decreased motor activity. Decreased motor activity often results in an apparently im- 


\section{SHAM \\ FGF $0 \quad$ FGF 5 \\ FGF 50}

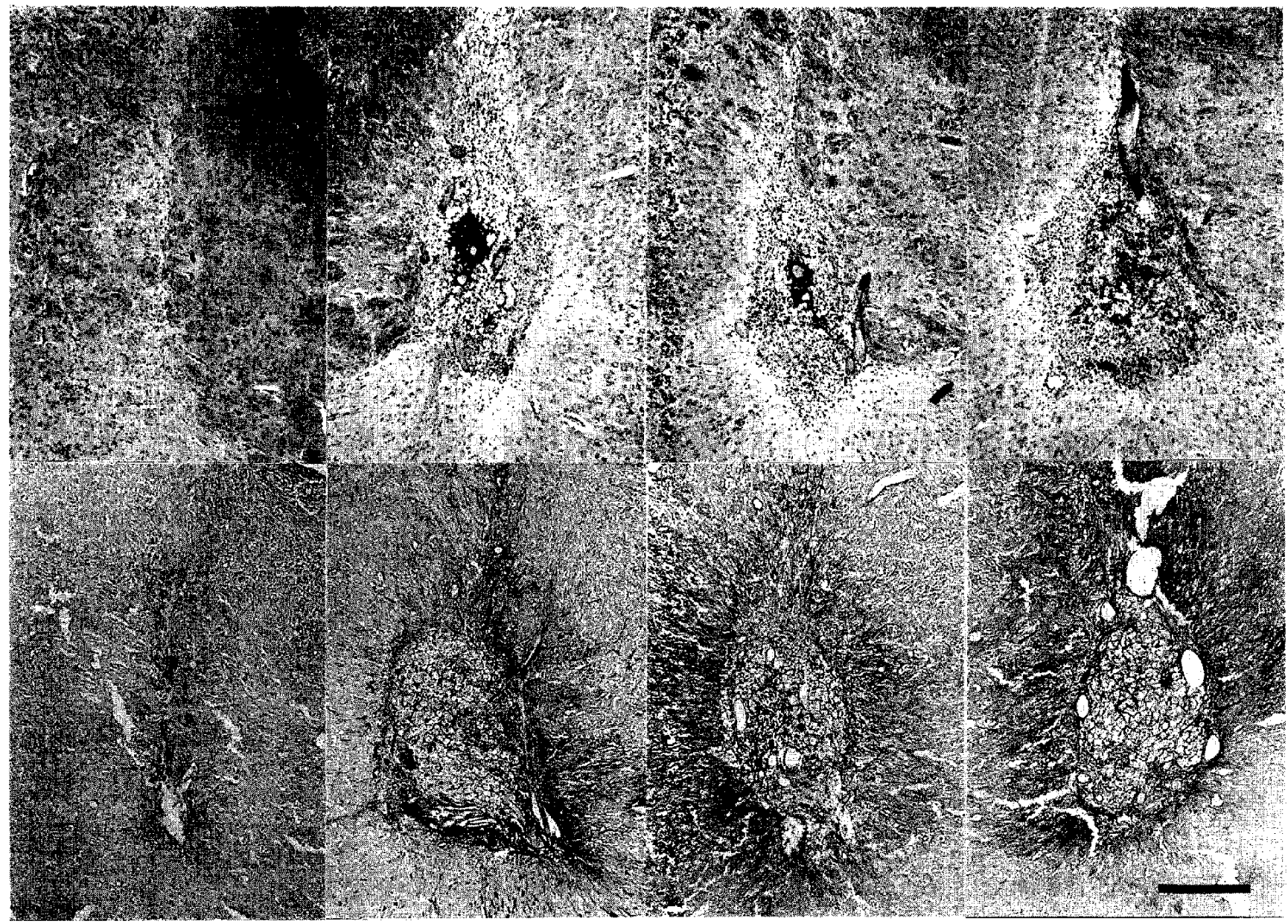

Fig. 4. Histological visualization of the lesioned area. Eight-micron coronal sections of the brain 31 days after operation were stained with H.E. (upper) or anti-GFAP antibody (lower). The bar represents $250 \mu \mathrm{m}$.

Table 3. Average volumes of the lesioned area

\begin{tabular}{lll}
\hline SHAM & $(\mathrm{n}=4)$ & $0.04 \pm 0.01$ \\
FGF 0 & $(\mathrm{n}=10)$ & $0.64 \pm 0.05$ \\
FGF 5 & $(\mathrm{n}=8)$ & $0.60 \pm 0.05$ \\
FGF 50 & $(\mathrm{n}=6)$ & $0.73 \pm 0.03$ \\
\hline
\end{tabular}

Results are given as means \pm S.E. $\left(\mathrm{mm}^{3}\right)$. See the legend to Fig. 2 for abbreviations.

proved learning performance in the passive avoidance task. In the present experiment, however, the BFlesioned group exhibited learning performance impairment in spite of their hypoactivity. Moreover, bFGF did not affect this decrement. Therefore, the observed ameliorating effect of bFGF in the present study was not an indirect one due to the change of motor activity. However, the cause of the motor activity decrease is still unknown.
Every mouse in the three lesioned groups finally attained the acquisition criterion after repeated training. Thus, BF lesioning suppressed memory function and delayed the acquisition of this task, but did not deprive the mice of their memory acquisition ability. The basic FGF-treated mice reached the acquisition criterion faster than the vehicle-treated controls, indicating that this factor, in some manner, mitigated the suppression of the memory function induced by BF Iesion. Bartus et al. (27) reported that animals which were routinely trained and tested on another task for 6 months following BF-lesion showed no deficit when subsequently tested with the stcp-through task. The authors also showed that the learning deficit in the stepthrough test persisted when BF-lesioned rats were detained in their home cage and received no training or task experience during the 6-month interval between surgery and the behavioral task (28). Thus, post-opera- 
tive exposure to some other learning task may enhance the memory function which is diminished by BF-lesioning. Basic FGF, in our experiment, may have acted as a chemical substance which can release the suppressed memory function. Abe et al. reported that the magnitude of long-term potentiation in hippocampal slices perfused with bFGF was larger than that in the control slices and suggested that bFGF might function as a modulator of synaptic transmission in the central nervous system (29). The memory acquisition-enhancing effect of this factor in the present study, however, may not be due to this acute effect, because behavioral tests were performed from 15 days after bFGF injection. Basic FGF might have brought about more chronic effects such as changes in receptor affinities or neural plasticity, which lead to the amelioration of BF lesion induced-memory disturbances. However, the precise chronic alterations remain to be elucidated.

Basic FGF has mitogenic activity on various types of cells. For example, it promotes astroglial proliferation, through which some trophic factors such as NGF are secreted. Furthermore, proliferating astrocytes are reported to synthesize and secrete NGF much more vigorously than resting cells (30). Thus, bFGF may very well have ameliorated the learning performance indirectly by stimulating glial cells to secrete NGF and/or other trophic factors.

After the fimbria fornix transection, bFGF, which was administered to the lesioned fibers, was reported to rescue the medial septal neurons $(18,19)$. In the current study, we completely destroyed the cell bodies in BF using thermolytic lesion. Thus, it is not likely that bFGF ameliorated the memory impairments by directly preventing death of damaged cholinergic cell bodies in this area. Indeed, no distinct pathological change was observed in and around the lesioned BF region after bFGF treatment. That is consistent with the finding that bFGF did not attenuate the lesion-induced reduction of ChAT activities in cerebral cortices. The significant decrease of ChAT activity in the cortex of the vehicle-treated $\mathrm{BF}$-lesioned group indicates that the learning deficit in this group is strongly related to attenuation of the cholinergic projection from the $\mathrm{BF}$ to the cerebral cortex. Indeed, acetylcholine esterase inhibitor has been reported to improve the memory performance of BF-lesioned animals (31). However, bFGF did not affect this ChAT decrement in spite of its amelioration of learning deficit. The persistent deficiency of ChAT activities was reported despite the behavioral recovery after BF-lesion (27). Thus, there is a possibility that bFGF improved lesion-induced memory deficits without affecting the BF-cortical cholinergic activity. Some monoaminergic nucleus project to their target areas through the pathway included in the BF $(32,33)$. On the other hand, the lesioning method used in our research was not specific for cholinergic cell bodies and passage fibers in the BF were also destroyed. Furthermore, the effects of bFGF are not cholinergic-specific, and it promotes neuron survival in cell cultures of almost all rat brain regions $(7,15-17,34)$. So, in the current study, it may be possible that bFGF prevents the death of neurons whose pathways exist in the BF. Since the central monoaminergic mechanisms are also suggested to play an important role in memory processes $(35,36)$, bFGF may ameliorate the memory disturbances indirectly through these monoaminergic systems.

In the posterior cortex, the higher dose of bFGF potentiated the decrease of ChAT activity. Furthermore, the average volume of the lesioned area was slightly greater than that of other lesioned groups. Thus, $50 \mathrm{ng}$ of bFGF may be a sub-critical dose for producing a malignant effect, which could account for the big S.E. in "acquisition" of the group treated with a high dose of $\mathrm{bFGF}$.

In conclusion, bFGF ameliorated the memory deficit without affecting cortical ChAT activity.

\section{REFERENCES}

1 McGeer, P.L., McGeer, E.G., Suzuki, J., Dolman, C.E. and Nagai, T.: Aging, Alzhcimer's disease, and the cholinergic system of the basal forebrain. Neurology 34, $741-745$ (1984)

2 Perry, E.K., Gibson, P.H., Blessed, G., Perry, R.H. and Tomlinson, B.E.: Neurotransmitter enzyme abnormalities in senile dementia. J. Neurol. Sci. 34, 247-265 (1977)

3 Wilcock, G.K., Esiri, M.M., Bowen, D.M. and Smith, C.C.T.: Alzheimer's disease; correlation of cortical choline acetyltransferase activity with severity of dementia and histological abnormalities. J. Neurol. Sci. 57, 407-417 (1982)

4 Altman, H.J., Crosland, R.D., Jenden, D.J. and Berman, R.D.: Further characterizations of the nature of the behavioral and neurochemical effects of lesions to the nucleus basalis of Meynert in the rat. Neurobiol. Aging 6, 125-130 (1985)

5 Friedman. E., Lerer, B. and Kuster, J.: Loss of cholinergic neurons in the rat neocortex produces deficits in passive avoidance learning. Pharmacol. Biochem. Behav. 19, 309-312 (1983)

6 Hepler, D.J., Wenk, G.L., Cribbs, B.L., Olton, D.S. and Coyle, J.T.: Memory impairments following basal forcbrain lesions. Brain Res. 346, 8-14 (1985)

7 Miyamoto, M., Kato, J., Narumi, S. and Nagaoka, A.: Characteristics of memory impairment following lesioning of the basal forebrain and medial septal nucleus in rats. Brain Res. 419, $19-31$ (1985)

8 Ridley, R.M., Baker, H.F., Drewett, B. and Johnson, J.A.: Effects of ibotenic acid lesions of the basal forebrain on serial reversal learning in marmosets. Psychopharmacology (Berlin) 86, $438-443$ (1985)

9 Ishihara, A., Saito, H., Ohta, H. and Nishiyama, N.: Basal 
forebrain lesioned mice exhibit deterioration in memory acquisition process in step through passive avoidance test. Japan. J. Pharmacol. 57, 329 - 336 (1991)

10 Baird, A., Esch, F., Mormede, P., Ueno, N., Ling, N., Bohlen, P. et al.: Molecular characterization of fibroblast growth factor: distribution and biological activities in various tissues. Recent Prog. Horm. Res. 42, 143-205 (1986)

11 Gospodarowicz, D., Neufeld, G. and Schweigerer, L.: Fibroblast growth factor. Mol. Cell. Endocrinol. 46, 187-204 (1986)

12 Janet, T., Grothe, C., Pettmann, B., Unsicker, K. and Sensenbrenner, M.: Immunocytochemical demonstration of fibroblast growth factor in cultured chick and rat neurons. J. Neurosci. Res. 19, 195-201 (1988)

13 Pettmann, B., Labourdette, G., Weibel, M. and Sensenbrenner, M.: The brain fibroblast growth factor (FGF) is localized in neurons. Neurosci. Lett. 68, $175-180$ (1986)

14 Finklestcin, S.P., Apostolides, P.J., Caday, C.G., Prosser, J., Phillips, M.F. and Klagsbrun, M.: Increased basic fibroblast growth factor (bFGF) immunoreactivity at the site of focal brain wounds. Brain Res. 460, 253-259 (1988)

15 Matsuda, S., Saito, H. and Nishiyama, N.: Effect of basic fibroblast growth factor on neurons cultured from various regions of postnatal rat brain. Brain Res. 520, 310-316 (1990)

16 Morisson, R.S., Sharma, A., de Vellis, J. and Bradshaw, R.A.: Basic fibroblast growth factor supports the survival of cerebral cortical neurons in primary culture. Proc. Natl. Acad. Sci. U.S.A. 78, $7205-7209$ (1986)

17 Walicke, P.A., Cowan, W.M., Ueno, N., Baird, A. and Guillemin, R.: Fibroblast growth factor promotes survival of dissociated hippocampal ncurons and enhances neurite extension. Proc. Natl. Acad. Sci. U.S.A. 83, 3012-3016 (1986)

18 Anderson, K.J., Dam, D., Lee, S. and Cotman, C.W.: Basic fibroblast growth factor prevents death of lesioned cholinergic neurons in vivo. Nature 332, 360-361 (1988)

19 Otto. D., Frotschier, M. and Unsicker, K.: Basic fibroblast growth factor and nerve growth factor administered in gel foam rescue medial septal neurons after fimbria fornix transection. J. Neurosci. Res. 22, 83-91 (1989)

20 Fischer, W., Wictorin, K., Björklund, A., Williams, LR. Varon, S. and Gage, F.H.: Amelioration of cholinergic neuron atrophy and spatial memory impairment in aged rats by nerve growth factor. Nature 329, $65-68$ (1987)

21 Seno, M., Sasada, R., Iwane, M., Sudo, K., Kurokawa, T. Ito, K. and Igarashi, K.: Stabilizing basic fibroblast growth factor using protein engineering. Biochem. Biophys. Res. Commun. 151, $701-708$ (1988)

22 Segawa, M., Saito, H. and Nishiyama, N.: Alteration in choline acetyltransferase and tyrosine hydroxylase activities of various brain regions after passive avoidance performance in mice. Biogenic Amines 7, 191 - 197 (1990)

23 Fonnum, F.: A rapid radiochemical method for the deter- mination of choline acctyltransferase. J. Neurochem. 24 $407-409$ (1975)

24 Bradford, M.M.: A rapid and sensitive method for the quantitation of microgram quantities of protein utilizing the principle of protein-dye binding. Anal. Biochem. 72, 248-254 (1976)

25 Dubois, B., Mayo, W., Agid, Y., Lemoal, M. and Simon, $\mathrm{H}$.: Profound disturbances of spontaneous and learned behaviors following lesions of the nucleus basalis magnocellularis in the rat. Brain Res. 338, 249-258 (1985)

26 Whishaw, I.Q., O'Connor, W.T. and Dunnet, S.B.: Disruption of central cholinergic systems in the rat by basal forebrain lesions or atropine: Effects on feeding, sensorimotor behavior, locomotor activity and spatial navigation. Behav. Brain Res. 17, 103 - 115 (1985)

27 Bartus, R.T., Pontecorvo, M.. Flicker, C., Dean, R.L. and Figueiredo, J.C.: Behavioral recovery following bilateral lesions of the nucleus basalis docs not occur spontaneously. Pharmacol. Biochem. Behav. 24, $1287-1292$ (1986)

28 Bartus, R.T., Flicker, C., Dean, R.L., Potecorvo, M., Figueiredo, J.C. and Fisher, S.K.: Selective memory loss following nucleus basalis lesions: long term behavioral recovery despite persistent cholinergic deficiencies. Pharmacol. Biochem. Behav. 23, 125-135 (1985)

29 Abe, K., Xie, F.-J. and Saito, H.: Human basic fibroblast growth factor enhances neuronal survival and modulates synaptic transmission in rat hippocampus. Eur. J. Pharmacol. 183, 2348 (1990)

30 Furukawa, S., Furukawa, Y., Satoyoshi, E. and Hayashi, K.: Synthesis/secretion of nerve growth factor is associated with cell growth in cultured mouse astroglial cells. Biochem. Biophys. Res. Commun. 142, 395-402 (1987)

31 Murray, C.L. and Fibiger, H.C.: Pilocarpine and physostigmine attenuate spatial memory impairments produced by lesions of the nucleus basalis magnocellularis. Behav. Neurosci. 100, $23-32$ (1986)

32 Nagatsu, I., Yoshida, M. and Karasawa, N.: Catecholaminergic neurons. Japan. J. Neuropsychopharmacol. 7, 191 207 (1985)

33 Sano, Y.: Serotonin neurons. Japan. J. Neuropsychopharmacol. 7, 237-253 (1985)

34 Morrison, R.S., Keating, R.F. and Moskal, J.R.: Basic fib roblast growth factor and epidermal growth factor exert differential trophic effects on CNS ncurons. J. Neurosci. Res. 21, $71-79$ (1988)

35 Muramoto, O.: Pharmacology of learning and memory. Japan. J. Neuropsychopharmacol. 6, $393-404$ (1984)

36 Araki, H., Uchiyama, Y., Kawashima, K. and Aihara, H.: Impairment of memory and changes in neurotransmitters induced by basal forebrain lesion in rats. Japan. J. Pharmacol. 41, $497-504$ (1986) 